\title{
Solving assembly line balancing problem using heuristic: A case study of power transformer in electrical industry
}

\author{
Nurhanani Abu Bakar ${ }^{1}$, Mohammad Fadzli Ramli ${ }^{2}$, Mohd Zakimi Zakaria ${ }^{3}$, \\ Tan Chan $\operatorname{Sin}^{4}$, Hafiz Masran \\ ${ }^{1,2,5}$ Institute of Engineering Mathematics, Universiti Malaysia Perlis, Malaysia \\ ${ }^{3,4}$ School of Manufacturing Engineering, Universiti Malaysia Perlis, Malaysia
}

\begin{tabular}{l} 
Article Info \\
\hline Article history: \\
Received Jun 19, 2019 \\
Revised Aug 2, 2019 \\
Accepted Aug 17, 2019 \\
\hline
\end{tabular}

\section{Keywords:}

Assembly line balancing

Bottleneck

Heuristic method

Idle time

Workstation

\begin{abstract}
Currently, problem in assembly line has created so much attention, particularly in manufacturing area. Similar to this case study as they faced with problems regarding workstation in production line of electrical industry. There exist some cases where workstations in assembly line are experienced with bottleneck and suffered from high idle time. Thus, four heuristic methods are used for minimizing number or workstations and improve the bottleneck problems at the same time. In this case study, LCR, RPW and LPT have successfully minimized the number of workstations from 19 to 16 . This solution has affected the layout of assembly line. Different from SPT that manage to improve the bottleneck among workstations by reducing number of workstations from 19 to 17 without changing the line layout. Therefore, both solution has brought an option for an engineer to choose which decision to be used in this assembly line in order to increase the line efficiency.
\end{abstract}

Copyright () 2020 Institute of Advanced Engineering and Science. All rights reserved.

\section{Corresponding Author:}

Name Nurhanani Abu Bakar,

Institute of Engineering Mathematics,

Universiti Malaysia Perlis,

02600 Arau, Perlis, Malaysia.

Email: nurhanani143@gmail.com

\section{INTRODUCTION}

In manufacturing industry, an assembly line (AL) is widely used in the manufacturing system to assembly different types of products [1]. The AL is known as set of tasks that assigned to a set of workstations based on the precedence diagram. The workstations are connected together by the transportation mechanism that can allowed the flow process to be carried out in one station to one station [2]. Authors from [3] described briefly the statement above and stated that an assembly line contains a sequence of works that connected by a conveyor moving at constant speed.

The process of sorting the right sequence order in assembly line seems to be significantly important for the manufacturing system [4] and critical part in production system [5]. This area of study are familiar with certain terms like processing time and cycle time. The processing is a total time required to perform a task, which is frequently said as working time. Different with cycle time that refer to the maximum working time that spent at each workstation. Normally, the cycle time is determined based on the product demand over time. In other words, the cycle time is the production rate required by the industry.

Since the application of AL is widely used in wide industry [6], numerous researchers argued that the balancing of assembly line has shown a great importance [5, 7]. The best way to optimize the assembly line is by reaching the line balancing. In addition, it is still worth to study the process of balancing the AL as 
this area still gaining in interest [5]. Baykasoğlu \& Dereli [8] achieved the line balancing by reducing the idle time between workstations. As different to [9] that aims to balance the AL by minimizing number of workstation with a give cycle time.

Besides, some authors agreed that problem of assembly line balancing falls into the NP-hard problem [10-12] and decision problem [13] that can be explored extensively. The problem in ALB arise during dividing tasks assignment to workstations based on precedence diagram due to achieve the objective function [14]. The remaining paper is organized as follows. Section 2 presents a review of literature on the SALBP. In third section, the problem regarding to this study are described well. Some parameters and two heuristic methods are explained briefly in Section 4. In Section 5, the computational results and analysis are presented and the concluding remarks are outlined in last section.

\section{LITERATURE REVIEW}

Simple Assembly Line Balancing Problem (SALBP) which also known as Assembly Line Balancing Problem (ALBP) [15]. Numerous authors have explored this area in these past years [16-19]. Nourmohammad and Eskandari [13] is classified the type of SALBP into two. The SALBP-1 aims to minimize workstation number with a given cycle time [20]. In contrast, SALBP-2 aims to minimize cycle time with a given number of workstation [21]. At this instant, some researchers might attracted to do a study on SALBP-3 [18] and SALBP-E [22]. The SALBP-3 aims to maximize the workload smoothing while SALBP-E aims to minimize number of workstation and cycle time simultaneously. Moreover, there are three types of assembly line model [23], which are single model [24], mixed model [25] and multi model [26]. Additionally, there also some classifications in term of arrangement of workstations. For example straight line [27], U-shaped [28], two-sided [29] and parallel workstation [30].

\section{PROBLEM DESCRIPTION}

One of the most common system used by manufacturing companies [31, 32] is the assembly line system. The assembly line system is widely applied in manufacturing automobile [33, 34], computer, electronic equipment [35] and others. However, there are two major problems faced by the companies when using the system; the bottleneck and the idle time [36]. The electrical industry is one of the example to show the problems clearly when using the assembly line system in manufacturing electrical appliances. One of the product is the PM 17-P, which is one type of power transformer manufactured by the industrial site using the assembly line system.

The factory manufactures the power transformer by using 19 workstations. As the assembly line system applied, this study deals with the problem faced during the entire process. For this factory, 29 seconds has been set by the industrial engineers for the cycle time in order to fix the production rate without any delay. This study has recorded that the efficacy rate of this assembly line system is $67 \%$. This rate is considered poor. It is because there are other competing companies has showed a better performance in producing the same product with a fewer number of workstations.

The SALBP in this electrical factory showed that they are facing with poor performance and less efficient. Both of these issues definitely will lead to higher costs and low productivity. The current performance SALBP of PM 17-P has been shown graphically in Figure 1. One of the workstation in Figure 1 is obviously facing with bottlenecks situations. Meanwhile the idling problems can be seen in other workstations. The operators have to wait for the next task from the previous workstation.

In order to achieve more balanced assembly line, both of the problems; the bottleneck and the idle time should be improved individually. The bottleneck problem should be solved by reducing the number of workstations meanwhile minimizing the idle time for each stations. Consequently, a better way should be applied in order to improve the efficiency of the existing assembly line. This approach will focus objectively on how to reduce costs and increase the production productivity. Therefore, this paper is focusing on three main issues in solving the SALBP, which are reducing the idle time, minimizing the number of the workstation and balancing the workload faced on each workstation. 


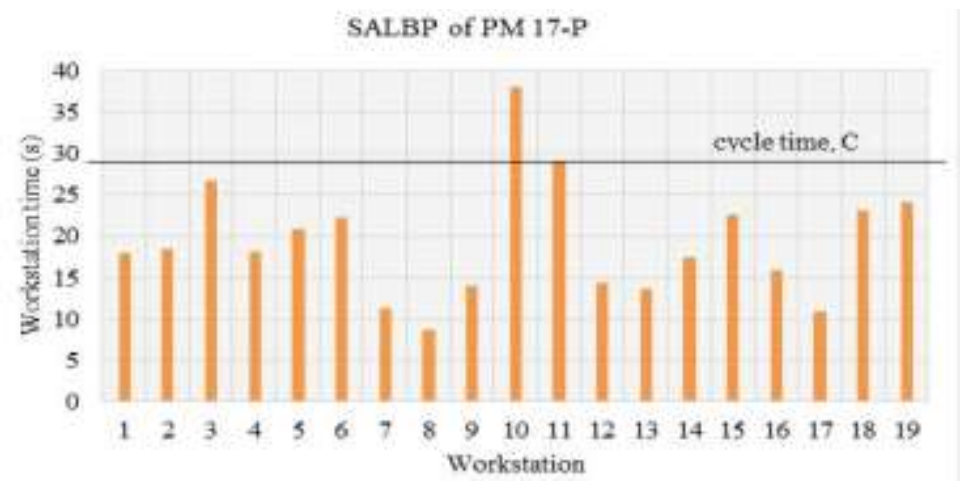

Figure 1. Graph for current system SALBP of PM 17-P

\section{METHODOLOGY}

Heuristic is a popular methods [37] and often used as a method for solving SALBP. This method was chosen because it suggests a solution based on the rules and procedures compared to others complex mathematical approaches. Solution using mathematical methods can be too complex especially when involving with bigger problems. Some authors like [38] stated that heuristic is the procedure for finding optimal solution.

So, Largest Candidate Rule (LCR), Ranked Positional Weight (RPW), Shortest Processing Time (SPT) and Longest Processing Time (LPT) are used to determine whether the number of workstations in the assembly line can be reduced or not. Together, overcome the bottlenecks and high idling times between workstations. The comparison of these methods with current system are analyzed in order to identify the best decision to optimize the assembly line. Table 1 shows the current system of assembly line that consists of 19 workstations and 27 tasks.

Table 1. Working Time and Workstation Time for SALBP of PM 17-P

\begin{tabular}{|c|c|c|c|c|}
\hline Workstation & Task & Task Description & Working Time (s) & Workstation Time (s) \\
\hline 1 & 2 & Secondary winding $(\sec 1)$ & 18.53 & 18.53 \\
\hline 2 & 3 & Secondary winding $(\sec 2)$ & 26.72 & 26.72 \\
\hline 3 & 4 & Secondary winding $(\sec 3)$ & 18.12 & 18.12 \\
\hline 4 & 5 & Secondary winding $(\sec 4)$ & 20.91 & 20.91 \\
\hline 5 & 6 & Secondary outer wrap & 22.26 & 22.26 \\
\hline \multirow{3}{*}{6} & 1 & Primary winding & 17.95 & \multirow{3}{*}{26.59} \\
\hline & 8 & Secondary bobbin soldering & 8.64 & \\
\hline & 7 & Primary bobin soldering & 11.28 & \\
\hline \multirow[t]{3}{*}{7} & 9 & Bobbin assembly & 5.50 & \multirow[t]{3}{*}{25.33} \\
\hline & 10 & Side tape & 8.55 & \\
\hline & 11 & E-core insert & 18.05 & \\
\hline \multirow[t]{2}{*}{8} & 12 & Hi-pot test & 8.24 & \multirow[t]{2}{*}{28.69} \\
\hline & 13 & Gluing & 2.40 & \\
\hline \multirow{3}{*}{9} & 14 & I-core insert & 9.27 & \multirow{3}{*}{29.10} \\
\hline & 15 & Welding & 19.83 & \\
\hline & 16 & Copper foil insert & 9.28 & \\
\hline \multirow[t]{2}{*}{10} & 17 & Core shield insert & 10.55 & \multirow[t]{2}{*}{23.62} \\
\hline & 18 & Bracket insert & 3.79 & \\
\hline 11 & 19 & Bracket clamping & 13.71 & 13.71 \\
\hline 12 & 20 & Functional test & 17.39 & 17.39 \\
\hline \multirow[t]{2}{*}{13} & 21 & Varnish & 22.50 & \multirow[t]{2}{*}{22.50} \\
\hline & 22 & VMI & 11.02 & \\
\hline \multirow[t]{2}{*}{14} & 23 & Labelling & 4.81 & \multirow[t]{2}{*}{26.68} \\
\hline & 24 & Touch-up soldering & 10.85 & \\
\hline \multirow{2}{*}{15} & 25 & Functional test & 21.36 & \multirow{2}{*}{23.02} \\
\hline & 26 & Packing & 1.66 & \\
\hline 16 & 27 & QC checking & 24.11 & 24.11 \\
\hline
\end{tabular}

Some parameters and formulas have been used in this paper in order to identify the best method that give the optimal solution. Terminologies and formulas are showed as: 


\subsection{Largest Candidate Rule (LCR)}

In this method, task $(i=1,2, \ldots, n)$ are arranged in descending order of workstation time from highest to lowest value. The assignment of tasks into workstations are sort from top to bottom based on previous constraint. When one task is selected to assign into the workstation, the next task selection will be repeated from the top list. This process are repeated until all the tasks are assigned to the workstations.

\subsection{Ranked Positional Weight (RPW)}

Ranked Positional Weights (RPW) is a method that sorting task based on weights value from largest to smallest. The value of weight is calculated by summing up the total task time with previous weights value. A task that has the highest weights value is selected first to assign to the workstation. Then, followed by a smaller RPW value. The task assignment should be considered by the previous constraint.

\subsection{Shortest Processing Time (SPT)}

Shortest Processing Time (SPT) method uses the criteria of selecting the shortest processing time or working time to assign to the workstation. In this method, the processing time for node without previous constraint and independent node are compared and the shortest processing time will be selected.

\subsection{Longest Processing Time (LPT)}

Longest Processing Time (LPT) method uses the criteria of selecting the longest processing time or working time to assign to the workstation. In this method, the processing time for node without previous constraint and independent node are compared and the longest processing time will be selected.

\section{RESULT AND DISCUSSION}

Theoretically, heuristic methods such as LCR, RPW, SPT and LPT are able to improve the assembly line balancing problem of PM 17-P. It is shown that these four heuristic methods succeed in balancing the assembly line better than the current system. Table 4 represents a comparison of analysis between heuristic methods and current system.

Based on Table 4, calculations of heuristic methods LCR, RPW, SPT and LPT have proposed two new system models SALBP of PM 17-P which are model of layout changes and model of layout without changes.

\subsection{Model I: Layout Changes Model}

The analysis of LCR, RPW and LPT bring up Model I that gives the same result for all three methods. However, the changes in the task specification of the operator and balancing result also affect the machine layout. Where the winding machine currently at workstation 1 had to be moved to workstation 6 . Whereas the change in task specification involve at workstations $6,7,8,9,10,14$ and 15. Table 2 shows the change in specification for this model.

This model only involves small layout changes without creating the complicated flow process. In addition, layout changes model uses 16 workstations and 17 operators in assembly line compare to current system which consists of 19 workstations and 19 operators.

\subsection{Model II: Layout Without Changes Model}

This model is a result of SPT heuristic analysis that only involves changes in task specifications on operators. This model does not change the machine layout and it uses 17 workstations with 17 operators only. Table 3 shows the specification of task on the operator for this model. Referring to Table 3, there are changes in the task specification on operator at workstations 8, 9, 10, 11 and 15. The change of assignment task occurred in workstations located at the center of the assembly line, which is at workstation 10 is proposed to overcome the bottleneck problems.

Theoretically, the heuristic method implemented on the SALBP of case studies succeeded in balancing the assembly line. The assembly line of 17-P PM should be improved to overcome the bottleneck condition and reduce the idling time between the workstations. These two problems had caused the imbalanced assembly line and unstable production.

Solutions using heuristic methods such as LCR, RPW, SPT and LPT are aimed to minimize the number of workstations in the assembly line, overcoming the bottleneck condition and the idling gap. This step is taken to make ALBP of PM 17-P more efficient and productive. Hence, two proposed models to improve the balancing of the assembly line PM 17-P is presented in this paper. In this case, the management team of this electrical industry have some idea to look at the best approach to encounter the problem. 
Model $\mathrm{I}$ is the solution by changing the position of the winding machine and change the task specification on the operator. While Model II only involves changes in the task specification on the operator.

Figure 2 illustrates the comparison of workstation time between current system, Model I and Model II, where the current system consists of 19 workstations. However, number of workstation can be reduced to 16 workstations by using Model I and 17 workstations by using Model II. Table 5 shows that variance for model I is the lowest value compared to current system and model II.

Table 2. Task Specification for Layout Changes (Model I)

\begin{tabular}{|c|c|c|c|c|}
\hline Workstation & Task & Task Description & Working Time (s) & Workstation Time (s) \\
\hline 1 & 2 & Secondary winding $(\sec 1)$ & 18.53 & 18.53 \\
\hline 2 & 3 & Secondary winding $(\sec 2)$ & 26.72 & 26.72 \\
\hline 3 & 4 & Secondary winding $(\sec 3)$ & 18.12 & 18.12 \\
\hline 4 & 5 & Secondary winding $(\sec 4)$ & 20.91 & 20.91 \\
\hline 5 & 6 & Secondary outer wrap & 22.26 & 22.26 \\
\hline \multirow{3}{*}{6} & 1 & Primary winding & 17.95 & \multirow{2}{*}{26.59} \\
\hline & 8 & Secondary bobbin soldering & 8.64 & \\
\hline & 7 & Primary bobin soldering & 11.28 & \multirow{4}{*}{25.33} \\
\hline \multirow[t]{3}{*}{7} & 9 & Bobbin assembly & 5.50 & \\
\hline & 10 & Side tape & 8.55 & \\
\hline & 11 & E-core insert & 18.05 & \\
\hline \multirow[t]{2}{*}{8} & 12 & Hi-pot test & 8.24 & \multirow[t]{2}{*}{28.69} \\
\hline & 13 & Gluing & 2.40 & \\
\hline \multirow{3}{*}{9} & 14 & I-core insert & 9.27 & \multirow{3}{*}{29.10} \\
\hline & 15 & Welding & 19.83 & \\
\hline & 16 & Copper foil insert & 9.28 & \\
\hline \multirow[t]{2}{*}{10} & 17 & Core shield insert & 10.55 & \multirow[t]{2}{*}{23.62} \\
\hline & 18 & Bracket insert & 3.79 & \\
\hline 11 & 19 & Bracket clamping & 13.71 & 13.71 \\
\hline 12 & 20 & Functional test & 17.39 & 17.39 \\
\hline \multirow[t]{2}{*}{13} & 21 & Varnish & 22.50 & \multirow[t]{2}{*}{22.50} \\
\hline & 22 & VMI & 11.02 & \\
\hline \multirow[t]{2}{*}{14} & 23 & Labelling & 4.81 & \multirow[t]{2}{*}{26.68} \\
\hline & 24 & Touch-up soldering & 10.85 & \\
\hline \multirow{2}{*}{15} & 25 & Functional test & 21.36 & \multirow{2}{*}{23.02} \\
\hline & 26 & Packing & 1.66 & \\
\hline 16 & 27 & QC checking & 24.11 & 24.11 \\
\hline
\end{tabular}

Table 3. Task Specification for Layout without Changes (Model II)

\begin{tabular}{|c|c|c|c|c|}
\hline Workstation & Task & Task Description & Working Time (s) & Workstation Time (s) \\
\hline 1 & 1 & Primary winding & 17.95 & 17.95 \\
\hline 2 & 7 & Primary bobin soldering & 11.28 & 11.28 \\
\hline 3 & 2 & Secondary winding $(\sec 1)$ & 18.53 & 18.53 \\
\hline 4 & 3 & Secondary winding $(\sec 2)$ & 26.72 & 26.72 \\
\hline 5 & 4 & Secondary winding $(\sec 3)$ & 18.12 & 18.12 \\
\hline 6 & 5 & Secondary winding $(\sec 4)$ & 20.91 & 20.91 \\
\hline \multirow[t]{2}{*}{7} & 6 & Secondary outer wrap & 22.26 & 22.26 \\
\hline & 8 & Secondary bobbin soldering & 8.64 & \\
\hline \multirow[t]{3}{*}{8} & 9 & Bobbin assembly & 5.50 & 22.69 \\
\hline & 10 & Side tape & 8.55 & \\
\hline & 11 & E-core insert & 18.05 & \\
\hline \multirow[t]{2}{*}{9} & 12 & Hi-pot test & 8.24 & 28.69 \\
\hline & 13 & Gluing & 2.40 & \\
\hline \multirow{3}{*}{10} & 14 & I-core insert & 9.27 & 2910 \\
\hline & 15 & Welding & 19.83 & 29.10 \\
\hline & 16 & Copper foil insert & 9.28 & \\
\hline \multirow[t]{2}{*}{11} & 17 & Core shield insert & 10.55 & 23.62 \\
\hline & 18 & Bracket insert & 3.79 & \\
\hline 12 & 19 & Bracket clamping & 13.71 & 13.71 \\
\hline 13 & 20 & Functional test & 17.39 & 17.39 \\
\hline \multirow[t]{2}{*}{14} & 21 & Varnish & 22.50 & 22.50 \\
\hline & 22 & VMI & 11.02 & \\
\hline \multirow[t]{2}{*}{15} & 23 & Labelling & 4.81 & 26.68 \\
\hline & 24 & Touch-up soldering & 10.85 & \\
\hline \multirow{2}{*}{16} & 25 & Functional test & 21.36 & \\
\hline & 26 & Packing & 1.66 & 23.02 \\
\hline 17 & 27 & QC checking & 24.11 & 24.11 \\
\hline
\end{tabular}


Table 4. Comparison of Analysis between Heuristic Methods and Current System

\begin{tabular}{lccccc}
\hline \multirow{2}{*}{ Analysis } & \multicolumn{4}{c}{ Heuristic Methods } & \multirow{2}{*}{ Current System } \\
\cline { 2 - 5 } & LCR & RPW & SPT & LPT & \\
\hline Minimum number of workstations, $S_{\min }$ & 16 & 16 & 17 & 16 & 19 \\
Number of operators, $w$ & 17 & 17 & 17 & 17 & 19 \\
Total idle time, $T_{i d}(\mathrm{sec} /$ /unit) & 96.72 & 96.72 & 125.72 & 96.72 & 173.72 \\
Efficiency line, $E_{b}(\%)$ & 79 & 79 & 74.5 & 79 & 67 \\
Balance delay, $d(\%)$ & 21 & 21 & 25.5 & 21 & 33 \\
Line balancing loss, LBL (\%) & 21.1 & 21.1 & 25.5 & 21.1 & 49 \\
Layout changes & Yes & Yes & No & Yes & - \\
Change of operator specification work & Yes & Yes & Yes & Yes & - \\
\hline
\end{tabular}

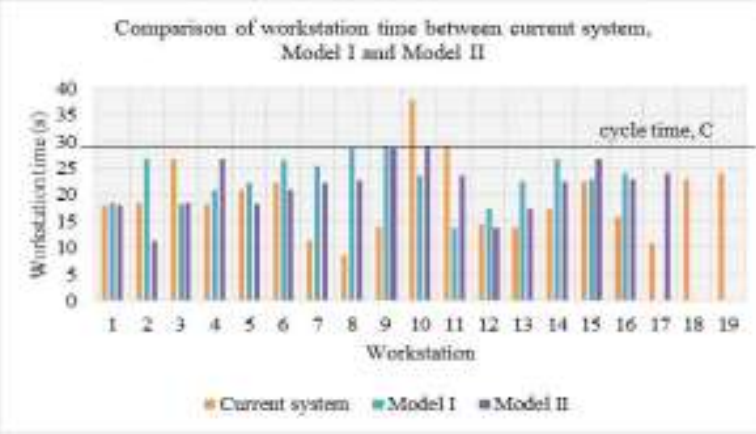

Figure 2. Comparison of workstation time between current system, Model I and Model II
Table 5. Comparison of Analysis between Current

\begin{tabular}{cccc}
\multicolumn{4}{c}{ System Model I, and Model II } \\
\hline Analysis & Current & Model & Model \\
& System & I & II \\
\hline Mean & 19.33 & 22.96 & 21.60 \\
Standard Deviation & 18.12 & 23.32 & 22.50 \\
Variance & 29.32 & 15.39 & 17.82 \\
\hline
\end{tabular}

\section{CONCLUSION}

The most common problem faced by the manufacturing companies is involving SALBP. Two main issues that can be seen in SALBP are the bottleneck problem and the idle gap between workstations. In order to solve these problems in the electrical industry, four heuristics methods are identified. The heuristic methods are capable in balancing the assembly line and improving the efficiency of the production. However, three of the heuristic methods gave results that led to the changes in layout and task specification against operators, which are the LCR, RPW and LPT. Meanwhile, the SPT methods reveal the solution that affecting the operator's task specifications without changing the layout line.

Hence, based on the results, two models are proposed for comparison; Model I and Model II. The first model, Model I represents the results from methods LCR, RPW and LPT. Those methods has made changes in operators' task specifications and the layout. Meanwhile the second model, Model II shows the results from SPT which only including the changes in operator task specifications without affecting the line layout. Both models are capable to reduce the number of workstations and the number of the operators. Therefore, the engineer will be able to decide between these two models to be applied to the AL in order to enhance line efficiency.

In future, it is recommended to conduct research on the simulation area by applying model I and II into this case study. Thus, the effect of layout changes and task specification could be analyzed. Also, the implication of this action might be recognized as either positive or vice versa.

\section{ACKNOWLEDGEMENTS}

The authors would like to acknowledge the support from Universiti Malaysia Perlis (UniMAP) and the Fundamental Research Grant Scheme (FRGS) under a grant number of FRGS/1/2016/TK03/UNIMAP/03/8 from the Ministry of Higher Education Malaysia and FRGS/1/2016/STG06/UNIMAP/03/6 from the Ministry of Higher Education Malaysia.

\section{REFERENCES}

[1] N. A. Bakar, M. F. Ramli, M. Z. Zakaria, C. S. Tan, H. Masran, and M. S. Saad, "A survey on research objective in assembly line balancing problem," in The Proceeding of Intelligent, Control and Automation Symposium, pp. 179-187, 2018.

[2] İ. Baybars, "A survey of exact algorithms for the simple assembly line balancing problem," Manage. Sci., vol. 32, no. 8, pp. 909-932, 1986. 
[3] A. Scholl and R. Klein, "Balancing assembly lines effectively-A computational comparison," Eur. J. Oper. Res., vol. 114, no. 1, pp. 50-58, 1999.

[4] M. Razif, A. Make, and M. F. Faisae, "Assembly line balancing using heuristic approaches in manufacturing industry," J. Mech. Eng., vol. 4, no. 2, pp. 171-185, 2017.

[5] M. Kammer Christensen, M. N. Janardhanan, and P. Nielsen, "Heuristics for solving a multi-model robotic assembly line balancing problem," Prod. Manuf. Res., vol. 5, no. 1, pp. 410-424, 2017.

[6] Z. Li, M. N. Janardhanan, P. Nielsen, and Q. Tang, "Mathematical models and simulated annealing algorithms for the robotic assembly line balancing problem," Assem. Autom., vol. 38, no. 4, pp. 420-436, 2018.

[7] J. Yu and Y. Yin, "Assembly line balancing based on an adaptive genetic algorithm," J. Adv. Manuf. Technol., vol. 48, no. 1-4, pp. 347-354, 2010.

[8] A. Baykasoğlu and T. Dereli, "Simple and u-type assembly line balancing by using an ant colony based algorithm," Math. Comput. Appl., vol. 14, no. 1, pp. 1-12, 2009.

[9] I. Kucukkoc, D. Z. Zhang, and E. C. Keedwell, "Balancing parallel two-sided assembly lines with ant colony optimisation algorithm," 2nd Symp. Nature-Inspired Comput. Appl. NICA 2013 - AISB Conv. 2013, no. April, pp. 21-28, 2013.

[10] S. Ghosh and R. J. Gagnon, "A comprehensive literature review and analysis of the design, balancing and scheduling of assembly systems," Int. J. Prod. Res., vol. 27, no. 4, pp. 637-670, 1989.

[11] S. D. Lapierre and A. B. Ruiz, "Balancing assembly lines: An industrial case study," J. Oper. Res. Soc., vol. 55, no. 6, pp. 589-597, 2004.

[12] A. Hamzadayi and G. Yildiz, "A simulated annealing algorithm based approach for balancing and sequencing of mixed-model U-lines q," Comput. Ind. Eng., vol. 66, no. 4, pp. 1070-1084, 2013.

[13] A. Nourmohammad and H. Eskandari, "Assembly line design considering line balancing and part feeding," Assem. Autom., vol. 37, no. 1, pp. 135-143, 2017.

[14] B. Zhou and Q. Wu, "A novel optimal method of robotic weld assembly line balancing problems with changeover times: a case study," Assem. Autom., vol. 38, no. 4, pp. 376-386, 2018.

[15] M. Gansterer and R. F. Hartl, "One- and two-sided assembly line balancing problems with real-world constraints," Int. J. Prod. Res., vol. 56, no. 8, pp. 3025-3042, 2017.

[16] G. Nicosia, D. Pacciarelli, and A. Pacifici, "Optimally balancing assembly lines with different workstations," Discret. Appl. Math., vol. 118, no. 1-2, pp. 99-113, 2002.

[17] O. Battaïa and A. Dolgui, "Reduction approaches for a generalized line balancing problem," Comput. Oper. Res., vol. 39, no. 10, pp. 2337-2345, 2012.

[18] M. Azizoğlu and S. İmat, "Workload smoothing in simple assembly line balancing," Comput. Oper. Res., vol. 89, pp. 51-57, 2018.

[19] D. Giglio, M. Paolucci, A. Roshani, and F. Tonelli, "Multi-manned assembly line balancing problem with skilled workers: A new mathematical formulation," IFAC-PapersOnLine, vol. 50, no. 1, pp. 1211-1216, 2017.

[20] M. Fathi, D. B. M. M. Fontes, M. Urenda Moris, and M. Ghobakhloo, "Assembly line balancing problem: A comparative evaluation of heuristics and a computational assessment of objectives," J. Model. Manag., vol. 13, no. 2, pp. 455-474, May 2018.

[21] H. P. Toroudi, M. S. Madani, F. Sarlak, and Y. G. Kanani, "A multi-objective method for solving assembly line balancing problem," Decis. Sci. Lett., vol. 6, no. 1, pp. 1-10, 2017.

[22] I. Belassiria, M. Mohamed, E. Said, C. Anass, and E. M. Zakaria, "Solving assembly line balancing problem using a hybrid genetic algorithm with zoning constraints," Int. J. Bus. Manag. Invent., vol. 6, no. 5, pp. 34-40, 2017.

[23] M. P. Groover, "Automation, production systems, and computer integrated manufacturing," Prentice Hall, pp. 815, 2007.

[24] L. Borba, M. Ritt, and C. Miralles, "Exact and heuristic methods for solving the robotic assembly line balancing problem," Eur. J. Oper. Res., vol. 270, no. 1, pp. 146-156, 2018.

[25] A. Biele and L. Mönch, "Hybrid approaches to optimize mixed-model assembly lines in low-volume manufacturing," J. Heuristics, vol. 24, no. 1, pp. 49-81, 2018.

[26] D. Krenczyk, B. Skolud, and A. Herok, "A heuristic and simulation hybrid approach for mixed and multi model assembly line balancing," in International Conference on Intelligent Systems in Production Engineering and Maintenance, pp. 99-108, 2017.

[27] J. Huo, Z. Wang, F. T. S. Chan, C. K. M. Lee, and J. O. Strandhagen, "Assembly line balancing based on beam ant colony optimisation," Math. Probl. Eng., vol. 2018, pp. 1-17, 2018.

[28] Z. Li, I. Kucukkoc, and Z. Zhang, "Branch, bound and remember algorithm for U-shaped assembly line balancing problem," Comput. Ind. Eng., vol. 124, pp. 24-35, 2018.

[29] A. Hamzadayi, "Balancing of mixed-model two-sided assembly lines using teaching-learning based optimization algorithm," Pamukkale Univ. J. Eng. Sci., vol. 24, no. 4, pp. 682-691, 2018.

[30] L. Tiacci, "Mixed-model u-shaped assembly lines: balancing and comparing with straight lines with buffers and parallel workstations,' J. Manuf. Syst., vol. 45, pp. 286-305, 2017.

[31] M. Yuan, H. Yu, J. Huang, and A. Ji, "Reconfigurable assembly line balancing for cloud manufacturing," J. Intell. Manuf., pp. 1-15, 2018.

[32] Y. Li and D. Coit, "Priority rules-based algorithmic design on two-sided assembly line balancing," Prod. Eng., vol. 12, no. 1, pp. 95-108, 2018.

[33] A. Kalra, S. Marwah, S. Srivastava, and R. Bhatia, "Productivity improvement in assembly line of automobile industry by reducing cycle time of operations," Int. J. Eng. Res. Technol., vol. 5, no. 05, pp. 28-31, 2016. 
[34] M. F. M. A. Hamzas, S. A. Bareduan, M. Z. Zakaria, S. Ghazali, and S. Zairi, "Implementation of ranked positional weight method (RPWM) for double-sided assembly line balancing problems," in AIP Conference Proceedings, vol. 1885, no. 1, p. 020183, 2017.

[35] K. Park, S. Park, and W. Kim, "A heuristic for an assembly line balancing problem with incompatibility, range, and partial precedence constraints," Comput. Ind. Eng., vol. 32, no. 2, pp. 321-332, 1997.

[36] N. T. Lam, L. M. Toi, V. T. T. Tuyen, and D. N. Hien, "Lean line balancing for an electronics assembly line," Procedia CIRP, vol. 40, pp. 437-442, 2016.

[37] M. F. M. A. Hamzas, S. A. Bareduan, and M. Z. Zakaria, 'A review on multi-objective optimization using evolutionary algorithms for two-sided assembly line balancing problems," ARPN J. Eng. Appl. Sci., vol. 11, no. 18, pp. 10882-10887, 2016.

[38] R. Marti and G. Reinelt, "Heuristic methods," in The linear ordering problem: exact and heuristic methods in combinatorial optimization, vol. 175, Springer Science \& Business Media, pp. 17-40, 2011.

[39] Ismail, Nanang and Nursalim, Iim and Saputra, Hendri Maja and Gunawan, Teddy Surya, "Implementation of fuzzy logic control system on rotary car parking system prototype," Indonesian Journal of Electrical Engineering and Computer Science (IJEECS), vol. 12 (2). pp. 706-715, 2018.

\section{BIOGRAPHIES OF AUTHORS}
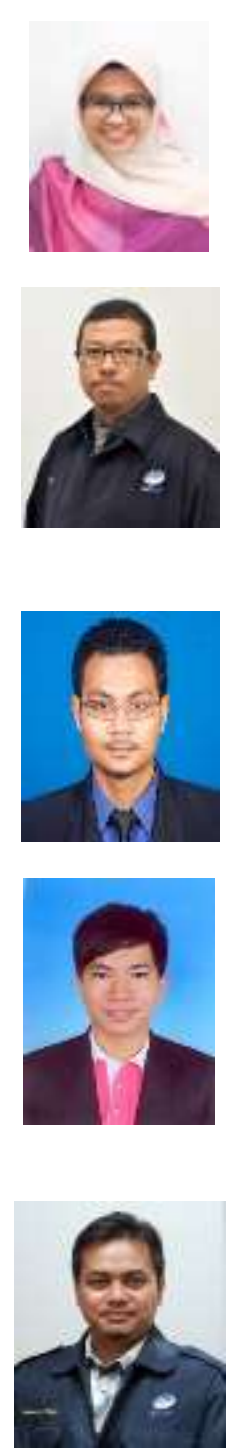

Miss Nurhanani Abu Bakar was born in Perlis, Malaysia on August 1995. She received Bachelor of Science in Computational Mathematics from 2014 to 2017. Currently she is pursuing MSc degree in Applied Mathematics in Universiti Malaysia Perlis, UniMAP. Her research interest includes application in mathematics, optimization and metaheuristics.

Dr. Mohammad Fadzli Ramli obtained his BSc. in Computer and MSc. In Information Technology from Universiti Teknologi Malaysia, Skudai, in 2000 and 2004, respectively, and a Ph.D. in Mathematics (Operational Research) from the same university, UTM, in 2012. Currently, he is a senior lecturer in the Institute of Engineering Mathematics at Universiti Malaysia Perlis (UniMAP). His research interests include optimization of vehicle routing problem, precisely capacitated arc routing problem in solid waste operation model, using statistics tools and metaheuristic methods. Besides, he is active in administrative which he is Chief Editor, Applied Mathematics and Computational Intelligence (AMCI).

Dr. Mohd Zakimi Zakaria was graduated with Bachelor of Engineering (Mechanical) and $\mathrm{PhD}$ (Mechanical Engineering) from Universiti Teknologi Malaysia in 2009 and 2013 respectively. His research interest is the area Control Engineering, System Identification, Artificial Intelligence. Currently he is a senior lecturer at School of Manufacturing Engineering, UniMAP. For professional membership, he is Graduate Member of Board of Engineers Malaysia (BEM) in 2 November 2009 and also a member in Majlis Rekabentuk Malaysia (MRM).

Dr. Tan Chan Sin received B.Eng. (Hons) Manufacturing Engineering from Universiti Malaysia Perlis in 2012. Then, he received Doctor of Philosophy in Manufacturing Engineering from Universiti Malaysia Perlis (UniMAP) in 2015. Currently he is working as senior lecturer in Universiti Malaysia Perlis (UniMAP). His research interest in Production Improvement, Lean Six Sigma, Manufacturing System Analysis, Simulation. His involvement in Professional Association including a graduate engineer of Board of Engineer Malaysia (BEM) and a member for both American Society Mechanical Engineering (ASME) and Malaysia Board of Technologist (MBOT).

Mr. Muhamad Hafiz bin Masran received the Bachelor of Science degree in Mathematics (2011) from University Technology Malaysia Skudai and M. Sc. in Engineering Mathematics (2015) from Universiti Malaysia Perlis (UniMAP). He is pursuing the $\mathrm{PhD}$ degree. Currently he is a lecturer in the Department of Institute of Engineering Mathematics, Universiti Malaysia Perlis (UniMAP). His research interests Operational Research especially in optimization. 